Commentary

\title{
A Pattern Language Approach to Learning in Planning
}

\author{
Remon Rooij * and Machiel van Dorst \\ Department of Urbanism, TU Delft, 2600 GA Delft, The Netherlands; E-Mails: r.m.rooij@tudelft.nl (R.R.), \\ m.j.vandorst@tudelft.nl (M.v.D) \\ * Corresponding author
}

Submitted: 26 February 2020 | Accepted: 26 February 2020 | Published: 6 March 2020

\begin{abstract}
The aim of this commentary is to present the position that a pattern language approach facilitates, even catalyzes (comparative) learning in planning for young professionals. This position builds on literature and is supported by the research work of six MSc Urbanism graduation projects, in which the students adopted a pattern language approach. Additionally, these alumni have been asked in retrospect to evaluate their pattern language experiences for their learning. The students say their pattern languages give focus, enrich the knowledge field, are flexible, and they do not prescribe what to do, or how to make a plan. Students see and appreciate the value of the simple, yet thoughtful structure of a pattern with both visual and verbal information. Additionally, they observe that this method enables the connection between disciplines, between theory and practice, and between stakeholders, and that, potentially, it is a helpful tool for all kinds of stakeholders. They refer to the method as a tool for communication, a tool for design and analysis, and a tool for learning.
\end{abstract}

\section{Keywords}

design; learning in planning; pattern language; planning; urbanism

\section{Issue}

This commentary is part of the issue "Comparative Planning, Learning and Evolving Governance" edited by Kristof Van Assche (University of Alberta, Canada), Raoul Beunen (Open University of the Netherlands, The Netherlands) and Stefan Verweij (University of Groningen, The Netherlands).

(C) 2020 by the authors; licensee Cogitatio (Lisbon, Portugal). This article is licensed under a Creative Commons Attribution 4.0 International License (CC BY).

\section{Introduction}

This article presents the position that a pattern language approach (Alexander, 1979; Alexander et al., 1977) facilitates, even catalyzes (comparative) learning in planning for young professionals, both graduate students and young practitioners. We argue that a tool such as a pattern language can genuinely help young professionals, as it contributes to their ability to organize complexity. For instance, a pattern language can help with documenting and comparing the lessons learned in projects, while on the other hand it can also transform scientific knowledge from academic research into planning and design principles supported by literature and empirical data. It results in a communicative portfolio of spatial principles, so-called 'patterns,' which help to assess planning and design situations, develop spatial plans and designs, and stimulate the debate and exchange of expertise among the involved actors.

Our position builds on literature about a pattern language approach and learning (see Section 2). It is supported by the comparison and evaluation of research conducted by six MSc Urbanism graduation students from TU Delft between 2010-2019, who adopted a pattern language approach for several planning and design assignments. Additionally, we have asked these alumni to retrospectively evaluate the benefits, values and limitations of a pattern language approach for their personal and professional learning. Section 3 explains the evaluation approach of the MSc thesis and interviews with our alumni, whereas Section 4 presents the results of those. We end this article with a reflection and consideration of the learning process of young professionals' experience via a pattern language approach. 


\section{A Pattern Language Approach: Learning in Planning and Design}

\subsection{A Pattern Language}

Christopher Alexander recognized the complexity and dynamic quality of design and planning. He developed a method to deal with this complexity; making the relation between the recurring nature of a problem and the process of designing a physical form that 'solves' that problem (Alexander, 1964, 1979). This method acknowledges the complexity of a spatial design, and at the same time divides this reality into comprehensive and understandable pieces. One piece is called a 'pattern' (Figure 1).

On the one hand, the pattern is underpinned with theory, while on the other hand, the pattern is clarified with a design sketch or an example. In one 'simple' overview a pattern presents a bridge between a problem and a solution. Yet, complexity kicks in again if one tries to relate patterns to other patterns. Every pattern usually relates to several other ones, very often in different ways (e.g., thematically, or via levels of scale). A pattern may even conflict with another pattern. If the relations between patterns are sketched out, we get a so-called 'pattern field' (Figure 2), which is just as complex as a real design or planning assignment (van Dorst, 2005). Such a pattern field can also be used to analyze sites and/or locations. The variety of patterns and their relations give the urban planning and design researcher a strong tool for a systematic assessment and for comparative learning, based on the question: Which patterns are present (or not) in a certain site/location?

The work of Alexander has been critiqued in the past (Dovey, 1990). Most of the time this critique was concerned with how Alexander saw, perceived, and defined good architectural quality and form. But we should not forget the valuable aspects of the pattern language method as discussed above. For us, these values are particularly relevant and interesting when considering the learning process of young professionals.

\subsection{Learning by Young Professionals}

Novice urbanists are often overwhelmed by the amount of conceptual knowledge and heuristics they need to master (Curry, 2017). The Cognitive Load Theory (CLT) tells us that our working memory has a limited capacity (Sweller, 1988). In order to be able to learn, people need room in this working memory. Learning stagnates when people must remember many different things at the same time (in their working memory), which happens, for example, when planners are confronted with a new planning situation. CLT explains that you need to use the capacity of your working memory for learning (as much as possible), among others by reducing the amount you use it for other things (Sweller, 1988). Here we must make a distinction between young and more experienced planning professionals, because they face dif- ferent challenges when learning. CLT shows that people solve problems by mapping out routes towards the solution (Newell \& Simon, 1972). Novices and (advanced) beginners must try out all kinds of routes to find the right one while experienced professionals know the 'correct' routes (Newell \& Simon, 1972).

In their work, Chi, Feltovich, and Glaser (1979) explain extensively that experts not only have more knowledge and experience than novices and beginners, but also that they approach problems differently. When confronted with a problem, people tend to dig into their memory to look for situations that you have met before. You look for points of recognition and you try to categorize the problem. Obviously, experienced professionals have a larger "frame of reference" (van Dooren, Boshuizen, van Merriënboer, Asselbergs, \& van Dorst, 2014), and thus have a richer "knowledge scheme" (Chi et al., 1979). Thus, experts not only have more prerequisite knowledge, but also a deeper conceptual knowledge. As a result, experts can find opportunities for a solution more efficiently and more systematically. For novices and beginners, solving problems takes a lot of cognitive capacity and usually lacks a systematic approach (Chi et al., 1979). Beginners can be helped by splitting up a problem in sub-problems, in smaller steps, or by a systematic way of working (Dreyfus \& Dreyfus, 2004; Sweller, 1988).

From the point of view of both planning and learning, it makes sense to say a few things about the difference between the language of images and words. Dual Coding Theory poses that our memory has two different processing systems, a verbal and non-verbal (Paivio, 1969). Everybody thinks with both systems and everybody benefits from the use of both. This also implies that so-called unimodal 'visual thinkers' or 'verbal thinkers' do not exist as such. Learning improves and occurs faster when both systems are used in relation to each other coherently and consistently (Paivio, 1969). And this, among others, is one of the strengths of a pattern language approach.

Within the complex process of developing a plan or design, the young professional needs ways to organize pieces of this multidimensional and open-ended puzzle. What this puzzle may look like is not clear on day one. Additionally, the formation of patterns can entail all kinds of activities, such as site analysis and/or the review of cases and literature. Patterns give young professionals freedom to create pieces before and during the process of making the puzzle. So, when a novice has found a first direction, inspiration or path towards a plan, he or she may start with creating steppingstones. Those patterns are, at the same time, simple tools to store knowledge, and are soundbites for solutions. They relieve the working memory, and thus give room to make a next (mental) step. And as every pattern connects verbal and non-verbal information, the young planner learns to see relations more explicitly, and learns to communicate those relations. 


\section{COGITATIO}
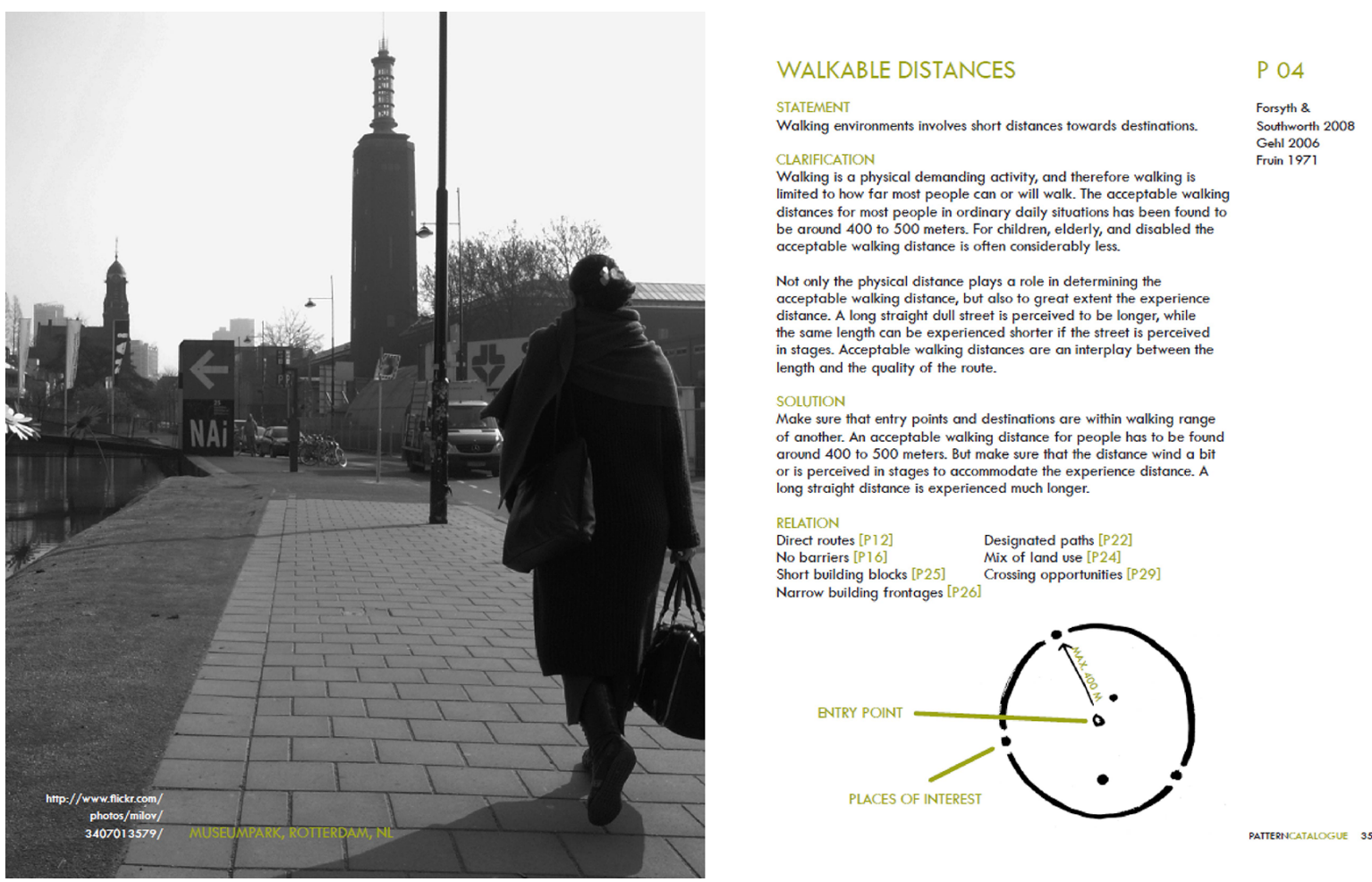

No barriers [P16]
Short building blocks [P25]
Narrow building frontages $[\mathrm{P} 26]$

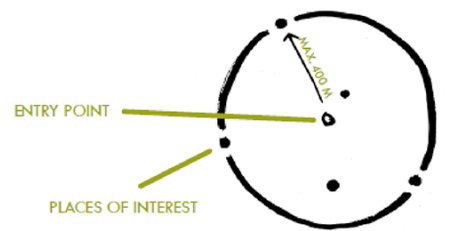

Figure 1. Example of a pattern (van Bellen, 2010b, pp. 34-35).

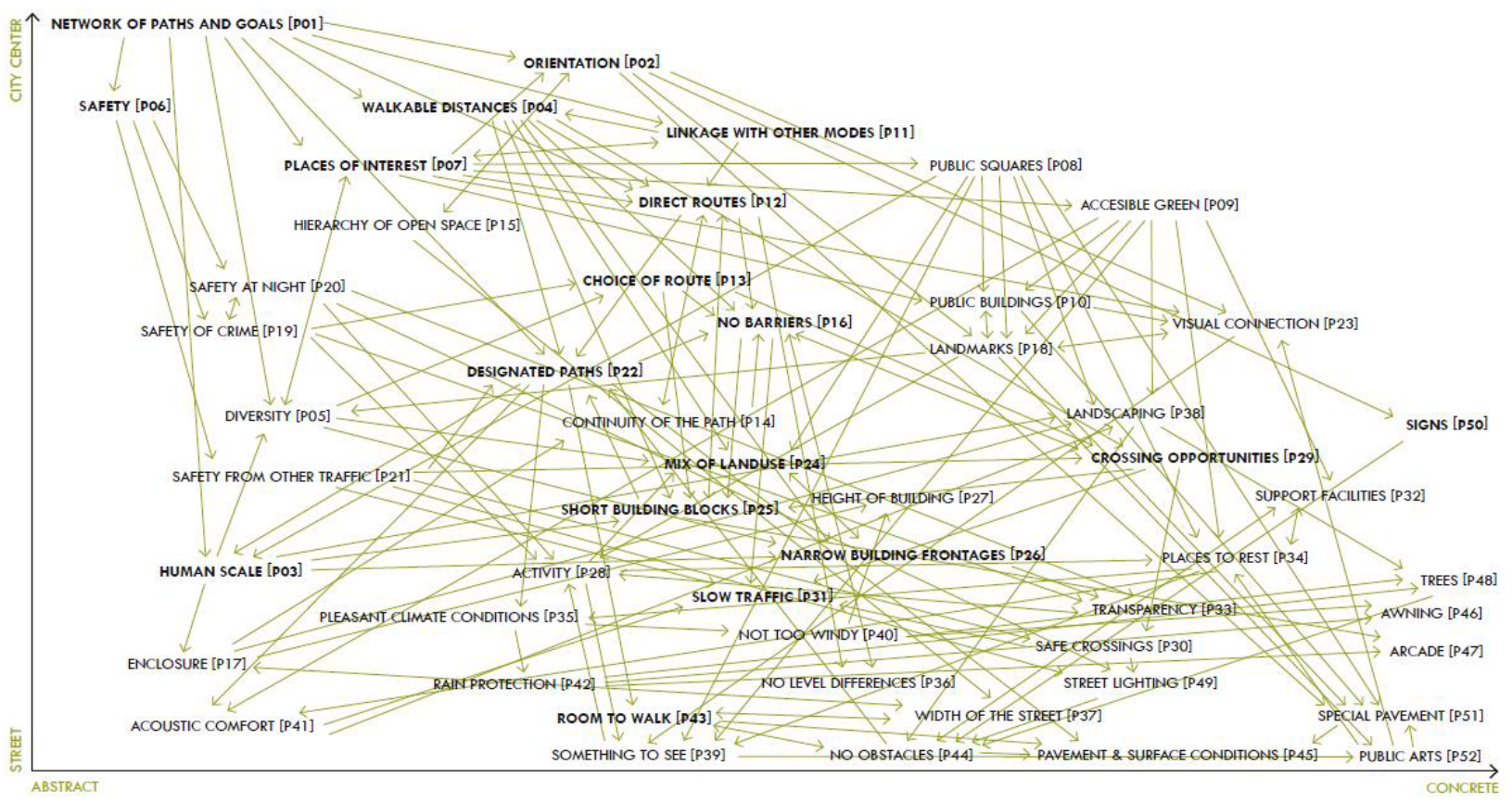

Figure 2. Example of a pattern field (van Bellen, 2010b, p. 25).

\section{The Analysis of Six MSc Urbanism Graduation Projects}

As urbanism teachers who experienced the positive nature of a pattern language approach for learning among our graduate students, we wanted to check if the students themselves are as positive as we are. We selected six TU Delft MSc Urbanism graduation projects, in which we were involved as mentors, and which used a pattern language approach for several complex planning and design assignments (Baak, 2019; Bruin, 2010; Koene, 2018; Koomen, 2014; van Bellen, 2010a; van Cammelbeeck, 2013).

At TU Delft, MSc Urbanism graduation students dedicate one full year (from the 2-year curriculum) to their graduation project. As part of the graduation process, 
students are asked to explicitly reflect on their experiences and integrate those in the final thesis. These reflections have been a valuable source of information on how students perceived the use of a pattern language approach during their graduation, and include the following themes:

- The relation of their project to the studio theme and studio approach;

- The relation between research and design, planning, and engineering;

- The research and design methods used;

- The scientific and societal relevance of the project;

- Ethical issues which the project brings forward.

The projects that we refer to were executed in the time frame of 2010-2019. We also wanted to know how 'our' students look at it now, in retrospect. We made contact again at the end of 2019 and asked all of them (via email) to evaluate again their pattern language experiences. This questionnaire included the following:

- Did you use patterns or a pattern language after your graduation?

- Has the use of a pattern language (then, later, now) been beneficial to your personal development and your own learning trajectory as urbanist?

- Is a pattern language for you a design tool, a communication tool, and/or a learning tool, or perhaps something else?

- Have your ideas changed about the value of a pattern language over the years?

- Do you see differences for and between urbanism students, young professionals, and more experienced professionals when using a pattern language?

\section{Pattern Language Approach: A Tool for Learning, Communication and Design}

\subsection{Comparison and Evaluation of the Reflections by Students on Their Thesis Projects}

In their thesis, students say their languages give focus, enrich the knowledge field, are flexible and adaptive, and can thus grow, change, and evolve over time. They are also clear what a pattern language is not; it does not prescribe what to do, or how to do it. The students clearly see a pattern language approach as a way to connect different scientific fields, to connect theory to practice, and to connect scientific knowledge to design and plan making:

At its core, this project aims to create bridges between the social sciences and the field of urbanism. Social sciences are disciplines that concern themselves with society and the relationships among the individuals that belong to this society, such as anthropology, eco- nomics, political science, psychology and sociology. The general consensus at this point in time is that, while the social sciences are undoubtedly relevant to the field of urbanism, they aren't connected in a way that enables us to effectively create an integral approach to prevalent socio-spatial issues. (Koomen, 2014, p. 30)

In relation to individual knowledge and learning, students express that they faced the challenge of exploring different and unfamiliar fields of knowledge, which itself, was a learning opportunity. Additionally, one student makes clear the power of a pattern language for transferring knowledge between individual actors and small teams of stakeholders:

Visual language refers to the integration of images and elements of images (visual elements) and words (verbal elements) into a single unit of communication. Images help to clarify difficult concepts and make complex relations easier to understand. It is important to use visual and verbal elements, so that the reader is guided to the right direction. (Baak, 2019, p. 85)

\subsection{Alumni Reflecting on Their Pattern Language Experience}

Four out of the six alumni responded to our questions sent by mail. They nicely express different ways in which a pattern language approach has been useful in their personal and/or professional development during and after graduation:

It made me realize that a pattern language approach is a method to make clear the variety of urban intervention proposals to people, who work on improving the city, independent of their (cultural, professional, personal) background.

It worked for me as designer in a different field now. That is the beautiful and powerful thing of a pattern language; it can be used in different fields.

For me a pattern language was useful...to discover the connection between the patterns is pivotal for an urbanist.

For me the usefulness was in the learning process on the research side, not so much on the design side. To support the principles, a lot of literature review was necessary, from which I learned a lot about analyzing scientific literature and academic writing.

In my learning process to become an urbanist it was useful. For my personal development not so much.

Two alumni who graduated more than five years ago explicitly show a more positive attitude towards a pat- 
tern language approach than they had during their graduation:

After my graduation I really started to see the actual value and contents of a pattern language.

When applying, I started to see the practical use, and this has only increased over time.

We, as urbanism student supervisors, have experienced several times that using a pattern language approach gives our students more 'control' over their design and planning assignments. The alumni see the nature of a pattern language in a broad sense: as a design tool, as a communication tool, and as a tool for learning. They point out that there are differences in value for the urbanist who developed a certain pattern language, for other urbanists, and for other professionals without an urban planning and design background:

The patterns served as inspiration for design.

It is an important tool for communication, besides being a design tool, in particular because of the simple and insightful structure.

A pattern language is both a design tool and a tool for learning...the development of a pattern language is a learning process, and in some ways even more valuable than the patterns themselves.

A pattern language is a good tool to start a conversation with involved stakeholders.

For other urbanists [than me] it can be a communication tool in the early stages of a project, and later on a design tool.

For professionals without design background...it can be both a communication tool and a learning tool, but to make the patterns easier to understand, I made a separate booklet for this group.

\section{Discussion}

In this article we took the position that a pattern language approach facilitates, even catalyzes (comparative) learning for young planning professionals, both graduate students and young practitioners. Pattern languages consist of patterns, which contain both visual and verbal information and concepts, and are presented in a coherent and consistent way. It enables the connection between scientific knowledge and planning and design interventions in practice. It is very helpful for communication and for non-urbanists who have relatively easy access to this piece of professional knowledge. Moreover, using patterns for systematically assessing and analyzing cases is a powerful tool for comparative learning in spatial plan- ning and urban design. On the one hand, using patterns as an analysis tool helps to define the (unique) planning assignment and/or design brief of a certain site/location. But on the other hand, it can also be used for a systematic inventory among cases which facilitates cross-case comparison, evaluation and reflection.

Our former urbanism students say their pattern languages give focus, enrich the knowledge field, and are flexible (i.e., the languages can grow, change and evolve over time, yet they do not prescribe what to do, or how to make a plan). They see the value of the simple, yet thoughtful structure of a pattern with both visual and verbal information. Additionally, they observe that this method enables the connection between disciplines, between theory and practice, and between stakeholders, and that, potentially, it is a tool to learn for all kinds of stakeholders. Logically, they all learn(ed) something different from their pattern language experiences.

All students chose to use a pattern language approach during their graduation. We did not tell them to do so; perhaps advised them to do so. Consequently, one might expect a relatively positive bias to this way of working. Additionally, we should be careful when drawing more general conclusions too quickly as such a small group of young professionals of course cannot represent all young urbanism professionals. That would require much more systematic research in urbanism education and practice. However, the students' reflections are strong indicators for a variety of important lessons on (comparative) learning in planning and design.

Our position presented is based on our personal experiences over decades of teaching urbanism, supported by the experiences of a small group of former students. The work has an exploratory and propositional nature but can be closely linked to concepts used in widely accepted models of learning. For us, it is clear that young urbanism graduates and practitioners clearly benefit from design and planning tools. Sometimes, the students start to appreciate those tools used during graduation (even more) after graduation. Young professionals face different mental challenges than seniors. Tools give young professionals a grip on complex situations, which more senior professionals might not need. The set of available tools for those novices is very limited; some can be too complex (e.g., working with scenarios), may be too random (e.g., reference projects), or could be missing a clear relation between scientific research and design (e.g., spatial site analyses).

One of our alumni wrote to us in the interview responses an anecdote of a senior urbanist and at the same time her urbanism teacher, telling her that "people who cannot design, develop a toolbox." For us, this colleague 'forgot' the amount of holistic, implicit and intuitive knowledge and skills that he has acquired over time, and, in particular, in comparison to an urbanism student. Less experienced urbanists and professionals from other fields look for ways to better understand urban design and planning knowledge, ideas, solutions, propos- 
als, thinking, and language. They look for clear communication from the experienced urbanism professionals, who quite often are not aware why they know what they know, and thus how to communicate that. The anecdote reminds us that being a successful and senior urbanist does not automatically qualify you to be a good urbanism teacher.

Alexander developed a method to express his opinion on spatial quality in a simple and understandable way. His work is for fellow professionals and for laymen. The effect of this effort is a method that transforms the complexity of planning and design into a language that is understandable for all; every pattern has a comprehensive structure- - hypothesis, its backup and its implication for intervention-and combines verbal information and non-verbal information. The side effect of his goals is a method that is appropriate as a tool for (comparative) learning, due to the fact that it is easily applicable for the novice urbanist and it supports communication between student and teacher, between young practitioner and coach, between researcher and plan maker.

\section{Conflict of Interests}

The authors declare no conflict of interests.

\section{References}

Alexander, C. (1964). Notes on the synthesis of form. London: Oxford University Press.

Alexander, C. (1979). The timeless way of building. New York, NY: Oxford University Press.

Alexander, C., Ishikawa, S., Silverstein, M., Jacobson, M., Fiksdahl-King, I., \& Angel, S. (1977). A pattern language. Towns, buildings, construction. New York, NY: Oxford University Press.

Baak, L. M. (2019). The neighbourhood medicine. Realizing a dementia friendly Ommoord (Unpublished MSc dissertation). Faculty of Architecture and the Built Environment and Faculty of Applied Sciences, TU Delft, The Netherlands.

Bruin, A. V. (2010). Future proofing late post-war neighbourhoods. Urban patterns for a socially sustainable Zevenkamp (Unpublished MSc dissertation). Faculty of Architecture and the Built Environment and Faculty of Applied Sciences, TU Delft, The Netherlands.

Chi, M. T. H., Feltovich, P. J., \& Glaser, R. (1979). Categorization and representation of physics problems by experts and novices. Cognitive Science, 5, 121-152.

Curry, T. (2017). Form follows feelings. The acquisition of design expertise and the function of aesthesis in the design process (Unpublished Doctoral dissertation). Faculty of Architecture and the Built Environment, TU Delft, The Netherlands.

Dovey, K. (1990). The pattern language and its enemies. Design Studies, 11(1), 3-9.

Dreyfus, H. L., \& Dreyfus, S. E. (2004). A phenomenology of skill acquisition as the basis for a Merleau-Pontian non-representationalist cognitive science. Berkeley, CA: University of California Berkeley.

Koene, M. (2018). Urban stress. Research into the reduction of urban stress through urban design (Unpublished MSc dissertation). Faculty of Architecture and the Built Environment, TU Delft, The Netherlands.

Koomen, I. M. I. C. (2014). Street smart: A social learning perspective on the restructuring of Oud-Charlois (Unpublished MSc dissertation). Faculty of Architecture and the Built Environment, TU Delft, The Netherlands.

Newell, A., \& Simon, H. A. (1972). Human problem solving. Englewood Cliffs, NJ: Prentice-Hall.

Paivio, A. (1969). Mental imagery in associative learning and memory. Psychological Review, 76, 241-263.

Sweller, J. (1988). Cognitive load during problem solving: Effects on learning. Cognitive Science, 12, 257-285.

van Bellen, S. (2010a). Citypedestrianized. Creating urban environments for people to walk (Unpublished MSc dissertation). Faculty of Architecture and the Built Environment, TU Delft, The Netherlands.

van Bellen, S. (2010b). Pattern catalogue. Patterns for urban environments for people to walk (Unpublished MSc dissertation). Faculty of Architecture and the Built Environment, TU Delft, The Netherlands.

van Cammelbeeck. C. I. (2013). Greying cities. Spatial strategies for residential neighbourhoods to promote active ageing (Unpublished MSc dissertation). Faculty of Architecture and the Built Environment, TU Delft, The Netherlands.

van Dooren, E., Boshuizen, E., van Merriënboer, J., Asselbergs, T., \& van Dorst, M. (2014). Making explicit in design education: Generic elements in the design process. International Journal of Technology and Design Education, 24, 53-71.

van Dorst, M. (2005). Een duurzame leefbare woonomgeving [A sustainable living environment]. Delft: Eburon.

\section{About the Authors}

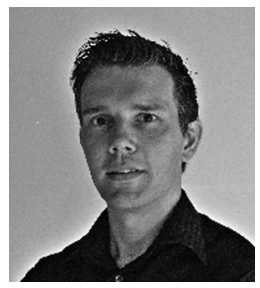

Remon Rooij (PhD) is Associate Professor of Spatial Planning \& Strategy at TU Delft, Department of Urbanism, and the leader of faculty's bachelor Bouwkunde programme (1,400 students). Remon is specialized in the relation between urban mobility and health, and is interested in strategic spatial planning methods. Remon is leading the faculty-wide initiative on Research-on-Education-Innovation at the Faculty of Architecture and the Built Environment, which focuses on design education, academic skills for designers/engineers/planners, inter- and transdisciplinary learning environments, online and blended learning and teaching, and curriculum renewal and educational leadership. 


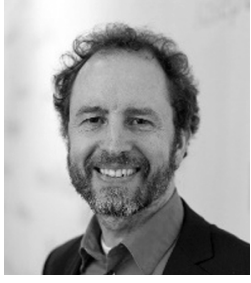

Machiel van Dorst (PhD) is Associate Professor of Environmental Technology \& Design at TU Delft, and Head of the Urbanism Department. Machiel is specialized in environment-behavior interactions, sustainable development, livability, and ecological design. In his research and teaching, Machiel focuses on issues of control, social safety, community design, child friendly cities, urban health, and stress reduction through design. 